\title{
Forest stand structure, productivity, and age mediate climatic effects on aspen decline
}

\author{
David M. Bell, ${ }^{1,3}$ John B. Bradford, ${ }^{2}$ and William K. Lauenroth ${ }^{1}$ \\ ${ }^{1}$ Department of Botany, 3165, University of Wyoming, 1000 E. University Ave, Laramie, Wyoming 82072 USA \\ ${ }^{2}$ U.S. Geological Survey, Southwest Biological Science Center, Flagstaff, Arizona 86011 USA
}

\begin{abstract}
Because forest stand structure, age, and productivity can mediate the impacts of climate on quaking aspen (Populus tremuloides) mortality, ignoring stand-scale factors limits inference on the drivers of recent sudden aspen decline. Using the proportion of aspen trees that were dead as an index of recent mortality at 841 forest inventory plots, we examined the relationship of this mortality index to forest structure and climate in the Rocky Mountains and Intermountain Western United States. We found that forest structure explained most of the patterns in mortality indices, but that variation in growing-season vapor pressure deficit and winter precipitation over the last 20 years was important. Mortality index sensitivity to precipitation was highest in forests where aspen exhibited high densities, relative basal areas, quadratic mean diameters, and productivities, whereas sensitivity to vapor pressure deficit was highest in young forest stands. These results indicate that the effects of drought on mortality may be mediated by forest stand development, competition with encroaching conifers, and physiological vulnerabilities of large trees to drought. By examining mortality index responses to both forest structure and climate, we show that forest succession cannot be ignored in studies attempting to understand the causes and consequences of sudden aspen decline.
\end{abstract}

Key words: climate effects; drought; Forest Inventory and Analysis; forest stand structure; mortality; Populus tremuloides; quaking aspen; Rocky Mountain West; sudden aspen decline; United States.

\section{INTRODUCTION}

Episodic forest and tree declines arising from climatic stress may increase greatly as climates change, potentially reshaping forest landscapes. For example, rising temperatures are stressing quaking aspen (Populus tremuloides Michx.) populations by exposing them to intense drought, and thus acute water stress (Hogg and Brandt 2005, Hogg et al. 2008, Anderegg et al. 2012a). In addition, stand characteristics impact tree mortality, such as increasing mortality with tree density as a result of inter- and intraspecific competition (Peet and Christensen 1987). Therefore, tree mortality, and thus forest decline, could arise from extrinsic (e.g., climate change) as well as intrinsic (e.g., competition) forcings. Because forest development, but not climate, can be modified by forest management, determining how forest structure mediates climate-induced declines could guide forest management in the face of climate change (Kashian et al. 2007).

Conspicuous and rapid quaking aspen mortality, sometimes called sudden aspen decline, is becoming increasingly common across western North America, impacting forest composition, function, and structure

Manuscript received 15 January 2014; revised 1 April 2014; accepted 25 April 2014; final version received 18 May 2014. Corresponding Editor: S. K. Chapman.

${ }^{3}$ Present address: Pacific Northwest Research Station, Forestry Science Laboratory, 3200 SW Jefferson Way, Corvallis, Oregon 97331 USA. E-mail: dmbell@fs.fed.us
(Worrall et al. 2013). In the Southern Rocky Mountains, aspen forests cover 4 million ha (Hicke et al. 2007), support greater biodiversity and productivity than do coniferous forests in the region (Gower et al. 1997, Simonson et al. 2001, Kuhn et al. 2011), and can include aspen clones hundreds or thousands of years old (Mitton and Grant 1996). Major die-offs in these forests would threaten regional carbon stocks and biodiversity and may result in the loss of some of the oldest organisms on Earth.

Aspen mortality arises from two primary classes of ecological processes: changes in forest structure during forest development and large-scale episodic declines often related to climate (Frey et al. 2004, Kulakowski et al. 2013). Although mortality in early-successional (i.e., young) aspen stands depends primarily upon intraspecific competition, such as self-thinning, mortality in older aspen stands typically arises from interspecific competition with encroaching conifers or density-dependent insect and disease outbreaks (Zegler et al. 2012). Given that many aspen stands in the western United States range from 60 to 160 years of age (Smith and Smith 2005, Binkley 2008), recent mortality patterns may be strongly influenced by forest succession.

The extent to which stand structure, age, and productivity mediate the impacts of climate in predisposing aspen to mortality will indicate under what conditions climate change may result in aspen decline. However, the relative influence of climate and succes- 
TABLE 1. Observed ranges of non-climatic variables for mortality index $(M)$, their ecological impact on aspen mortality, and the predicted effect of each on the mortality index.

\begin{tabular}{|c|c|c|c|}
\hline Variable & $\begin{array}{l}\text { Observed } \\
\text { range }\end{array}$ & Ecological impact/question & $\begin{array}{c}\text { Predicted } \\
\text { effect }\end{array}$ \\
\hline $\ln$ (tree density), $N$ & $0.69-4.90$ & density-dependent mortality (no. trees/ha) & + \\
\hline Relative basal area, $R$ & $0.01-1.00$ & $\begin{array}{l}\text { mortality may vary with aspen dominance due to interspecific } \\
\text { competition }\end{array}$ & - \\
\hline Basal area increment, $B\left(\mathrm{~m}^{2} \cdot \mathrm{ha}^{-1} \cdot \mathrm{yr}^{-1}\right)$ & $0.01-0.88$ & $\begin{array}{l}\text { high-productivity sites may have reduced mortality due to } \\
\text { reduced stress }\end{array}$ & - \\
\hline Quadratic mean diameter, $Q(\mathrm{~cm})$ & $12.95-54.67$ & size-dependent mortality & + \\
\hline Stand age, $A(\mathrm{yr})$ & $42-238$ & $\begin{array}{l}\text { highest in early-successional stands (i.e., self-thinning of } \\
\text { young trees) or in old stands (i.e., decline of mature trees) }\end{array}$ & $-1+$ \\
\hline $\begin{array}{l}\text { Growing-season vapor pressure deficit, } \\
\qquad V(\mathrm{kPa})\end{array}$ & $0.72-2.07$ & $\begin{array}{l}\text { drier regions, as defined by high vapor pressure deficits } \\
\text { during the growing season and low winter precipitation (in }\end{array}$ & + \\
\hline $\ln$ (winter precipitation), $P$ & $3.96-6.60$ & $\mathrm{~mm}$ ), may experience greater mortality & - \\
\hline
\end{tabular}

Note: For the ln-transformed variables, tree density is no. trees/ha; precipitation was measured in $\mathrm{mm}$.

sional dynamics on recent aspen decline, and the potential for interactions, remains uncertain (Zegler et al. 2012). To better understand the role of climate and successional dynamics in predisposing forest stands to recent aspen declines, we examined the relationship of aspen snag densities with forest structure and climate in forests of the Rocky Mountains and Intermountain West of the United States (Rocky Mountain West hereafter; Appendix A: Fig. A1). Using data from the U.S. Forest Service Forest Inventory and Analysis (FIA) program, we quantified the relationship between observed recent aspen mortality and measures of local forest successional and cohort dynamics (i.e., forest structure, age, and productivity) vs. measures of potential climatic stress that would contribute to largescale episodic declines (i.e., drought). Our objectives were (1) to characterize the relationship between recent aspen mortality and forest structure, age, and productivity, and (2) to determine whether, after accounting for structure, age, and productivity, recent aspen mortality was related to spatial variation in drought severity across western North America.

\section{Methods}

\section{Study area and data collection}

We restricted this study to the Rocky Mountain West, a $2236623 \mathrm{~km}^{2}$ region including Arizona, Colorado, Idaho, Montana, New Mexico, Nevada, Utah, and Wyoming. We restricted the sample area for three reasons: (1) in the western United States, most of the aspen populations are found in these eight states; (2) these populations appear to be genetically distinct from populations in Canada and the northeastern United States (Mock et al. 2012); and (3) all FIA plots in this region were sampled by the Rocky Mountain Research Station, minimizing differences in sampling protocols. To maximize the opportunity of observing climatic impacts on mortality indices, we examined FIA plots measured after 2002, when regional declines were observed to increase (Hogg et al. 2008, Worrall et al. 2008). The FIA is a forest inventory network used to characterize forest conditions across the United States using one $653-\mathrm{m}^{2}$ plot representing $\sim 25 \mathrm{~km}^{2}$ (Woudenberg et al. 2010). On each plot, individual trees at least $12.7 \mathrm{~cm}$ in diameter are identified to species and measured for a variety of variables, including diameter and mortality status (i.e., live or standing dead). Stand age was estimated based on tree rings. Young stands ( $<40$ years old) were excluded to avoid biases associated with newly recruited stands. We identified 841 FIA plots within the study area where aspen was present and stand age could be estimated.

FIA plot data were used to calculate measures of stand structure, age, and productivity (Table 1). Based on measurements of individual trees, we calculated the number of live and dead aspen for each FIA plot. Given that aspen snags tend to fall within 5-20 years (Lee 1998, Hart and Hart 2001, Ganey and Vojta 2005, Angers et al. 2010), we used mortality index ( $M$; i.e., the ratio of dead aspen tree density to the density of all aspen trees) as a proxy for recent mortality occurring prior to stand measurement. We calculated aspen tree density $(N)$, total stand basal area, aspen relative basal area $(R$; ratio of aspen to total basal area), and aspen quadratic mean diameter $(Q$; diameter of the average basal area tree). We interpreted the maximum reported tree age as the age of the stand $(A)$. Basal area increment $(B)$, a proxy for site productivity, was calculated as stand basal area divided by stand age. To achieve normality, tree density was ln-transformed.

Although extreme weather events can incite tree mortality, average climate predisposes certain populations to greater risk (Frey et al. 2004). Because dead aspen trees stand for several years or more (5-20 years), the mortality index $M$ integrates mortality events over several years. We assume that climate averaged over 20 years is appropriate for evaluating how climate predisposes aspen to mortality. Therefore, we calculated means for recent (i.e., 20 years prior to plot measurement) growing-season vapor pressure deficit and lntransformed winter precipitation, variables strongly related to tree growth across the region (Williams et al. 2012), for each FIA plot from the 2.5 arc-minute monthly historical PRISM climate database (PRISM Climate Group 2008). Climate variables were highly 
correlated with 40-year mean vapor pressure deficit and ln-transformed winter precipitation (Pearson correlation $r=0.98$ and $r=0.99$, respectively)

\section{Statistical analysis}

Because aspen mortality increases with both aspen and conifer density and climate influences both the magnitude and form of mortality patterns in aspen forests (Kashian et al. 2007), we used a Bayesian logistic regression framework to evaluate interactions among non-climatic and climatic effects. The logistic regression framework assumes that the number of recently dead trees, $y$, depends on the total number of aspen trees, $n$, as well as variation in the climatic and non-climatic environment as represented by a logit link function. By explicitly incorporating interactions, we accounted for the fact that mortality index responses to any single variable may be conditional on the state of the other variables. Bayesian model-fitting provides flexibility for model selection, such as the calculation of posterior model probability, and straightforward methods for prediction, such as sampling parameter estimates from Markov chain Monte Carlo output to evaluate uncertainty (see Appendix B).

To examine both climatic and non-climatic influences on recent aspen mortality, the mortality index $M$ was modeled as a binomial distribution with a logit link function $(y \sim \operatorname{Binomial}[n, M])$, where $y$ was the number of recently dead trees, $n$ was the summed number of live and dead trees, the predicted mortality index $M=(1+$ $\exp [-\mathbf{x} \boldsymbol{\beta}])^{-1}$, where $\mathbf{x}$ was a vector of covariates including main and interaction effects for non-climatic and climatic variables (Table 1), and $\boldsymbol{\beta}$ was a vector of regression parameters. Interaction terms were calculated with centered covariates to reduce collinearity. To limit the number of models to compare, we used a stepwise, generalized linear regression with a Bayesian information criterion to identify the important non-climatic variables and their interactions (glm and stepAIC functions in R) (R Development Core Team 2010); see Supplement for R code. Based on this initial data exploration, the minimal model used in this analysis incorporated the non-climatic variables (Table 1) as well as interaction between forest stand structural variables $(N \times R, N \times Q$, and $R \times Q)$, forest stand structure and age $(N \times A$ and $R \times A)$, forest stand structure and productivity $(N \times B, R \times B$, and $Q \times$ $B)$, and forest stand age and productivity $(A \times B)$. We then explored the interactions between climatic and nonclimatic effects using Bayesian model-fitting and selection (Appendix B).

\section{Results}

Because each variable was incorporated in at least one interaction of the selected model (Appendix B), mortality index responses to each variable were conditional on other factors (Fig. 1). For example, mortality index increased with aspen density, but the transition from stands of low mortality to stands of high mortality index occurred at lower densities when relative basal area, basal area increment, and stand age (Fig. 1a-c) were low and when quadratic mean diameter was high (Fig. 1d). As illustrated by these interactions, mortality index responses generally increased with aspen tree density (Fig. 1a-d) and quadratic mean diameter (Fig. 1d, e, h), but decreased with relative basal area (Fig. 1a, e-g), basal area increment (Fig. 1b, g-i), and stand age (Fig. 1c, f, i).

Climate effects on mortality index were small, although there were interactions of vapor pressure deficit with stand age as well as ln-transformed precipitation with lntransformed tree density, relative basal area, quadratic mean diameter, and basal area increment (Fig. $1 \mathrm{j}-\mathrm{n}$; see Appendix B: Table B1). As a result of these interactions, the sensitivity of mortality index to decreasing precipitation and increasing vapor pressure deficit indicated that the climate effects differed among plots with divergent forest structure, productivity, and age (Fig. 2). Decreases in precipitation were predicted to decrease mortality indices of plots with low tree density, relative basal area, quadratic mean diameter, and basal area increment (Fig. $2 \mathrm{a}-\mathrm{d}$ ), whereas increases in vapor pressure deficit were predicted to increase mortality indices in young stands (Fig. 2e). Correlations among the covariates ranged from -0.33 to 0.67 , with the greatest correlations being observed between $\ln$-transformed tree density and relative basal area, and all other correlations less than 0.45 (Appendix A: Fig. A2).

\section{DisCUSSION}

Patterns in the aspen mortality index across FIA plots imply that climate played a role in recent aspen declines, but, at the plot level, forest stand structure and productivity mediate mortality responses to climate. Recent trends of aspen decline and mortality identified by remote sensing have indicated greater aspen vulnerability in warmer, drier climates, presumably because of increased likelihood of drought (Worrall et al. 2013). Aspen decline in the region has been linked to both forest successional status and climate (Worrall et al. 2008, 2010, Zegler et al. 2012), although the relative strength and interacting effects of these factors are not well documented. Although we found that mortality index was related to growing-season vapor pressure deficit and winter precipitation (Appendix B: Table B1), the effects were small relative to forest stand structure, age, and productivity (Fig. 1). Furthermore, variation between plots in sensitivity of mortality index to decreases in precipitation and increases in vapor pressure deficit suggests that aspen responses to drought were conditional on forest stand structure and productivity (Fig. 2). Predicting aspen decline with climate will depend on species composition, tree size, and forest productivity.

Differences in the sensitivity of the mortality index to changes in climate highlight the importance of both physiological vulnerability and competition as possible drivers of sudden aspen decline. The strong, positive relationship between sensitivity of mortality index to 

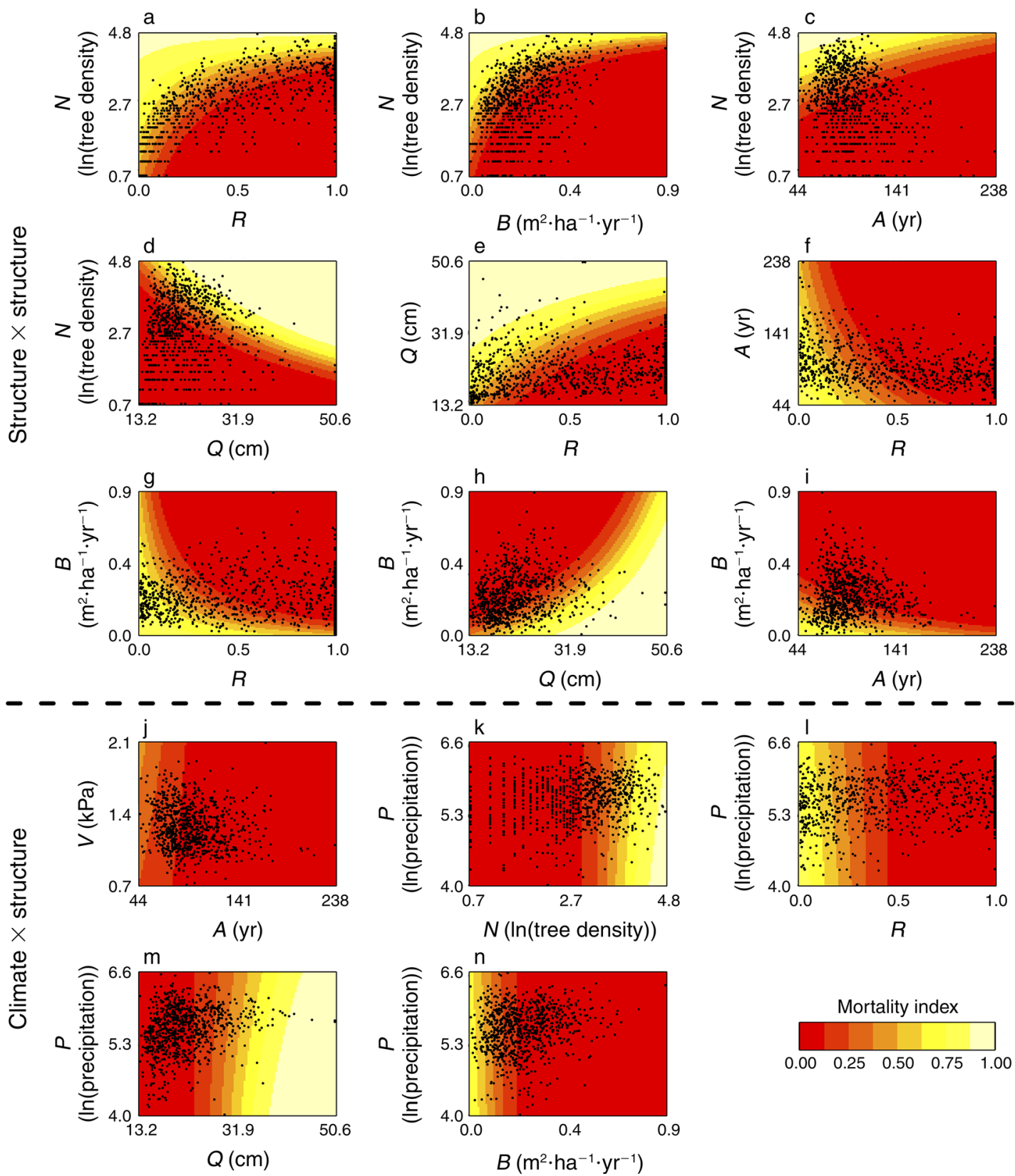

FIG. 1. Aspen mortality index $(M)$ was more sensitive to variation in forest structure compared with climate, as indicated by the strength of interactions (see also Appendix B: Table B1). Mean predicted mortality indices (low, red; high, yellow) for aspen are presented for $(\mathrm{a}-\mathrm{i})$ structure $\times$ structure interactions and $(\mathrm{j}-\mathrm{n})$ climate $\times$ structure interactions. Black points indicate observed values for the aspen forests in this study. For the purposes of these predictions, all structural and climate variables other than those indicated on the axes of each panel were held constant at their observed means. Variables are $N$, tree density (ln-transformed number/ha); $R$, relative basal area (a proportion); $B$, basal area increment; $A$, stand age; $Q$, quadratic mean diameter; $V$, vapor pressure deficit; and $P$, winter precipitation (ln-transformed; originally measured in $\mathrm{mm}$ ).

decreased winter precipitation and tree size (Fig. 2c) indicated that large trees were more sensitive to drought, possibly due to increasing vulnerability as trees grow larger (Worrall et al. 2008) and become more exposed (Worrall et al. 2010). Canopy losses, and resulting mortality, are related to fine-root mortality and xylem cavitation during and following extreme drought condi- tions (Worrall et al. 2010, Anderegg 2012, Anderegg et al. 2013), implying that tree size and physiology influence aspen drought vulnerability.

Sensitivity of mortality index to drought depended on tree density and aspen dominance, indicating that the competitive environment experienced by aspen mediates the influence of climate on mortality. Aspen stands were 

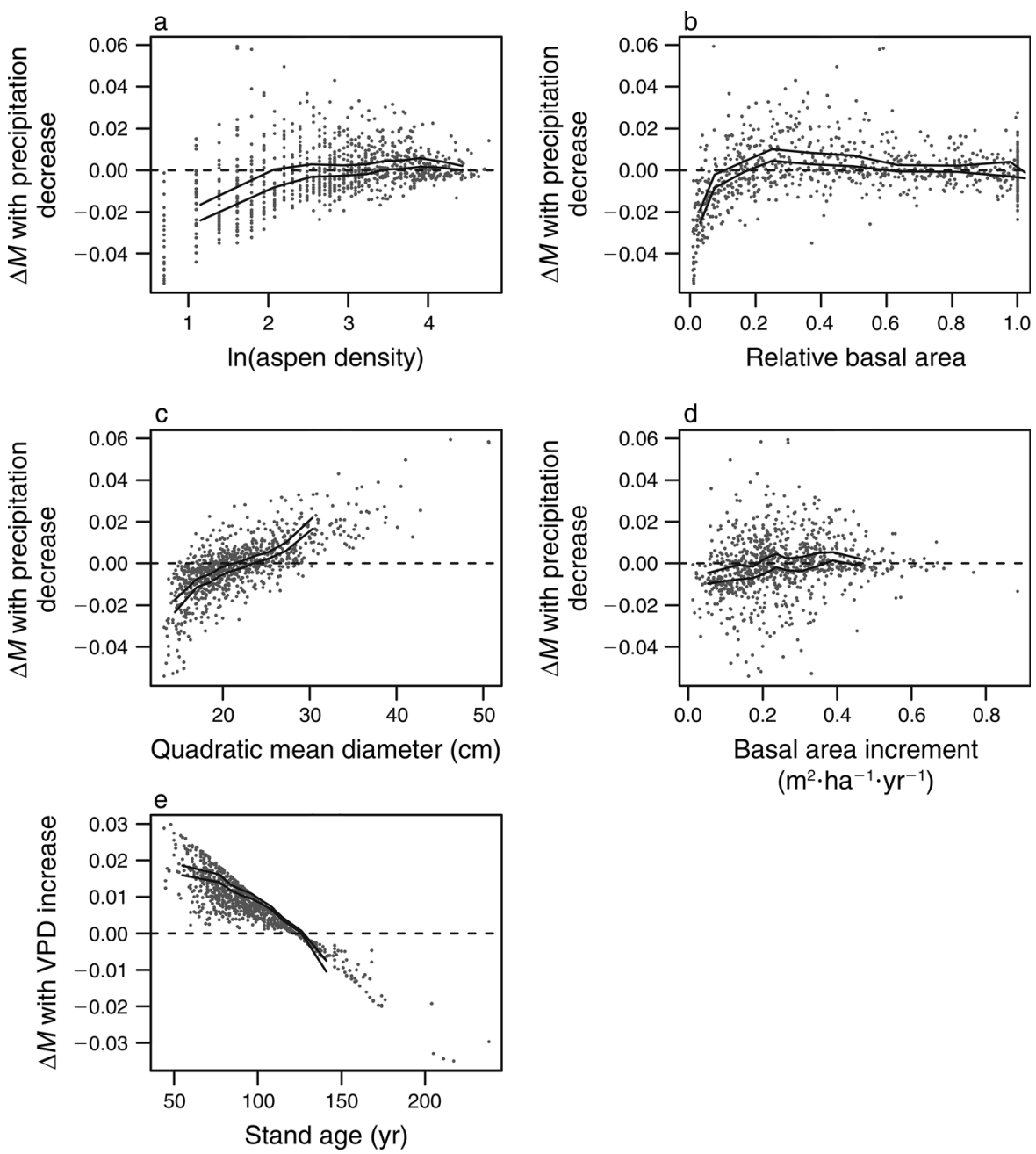

FIG. 2. The sensitivities of mortality index $M$ to (a-d) decreasing winter precipitation and (e) increasing growing-season vapor pressure deficit indicate the potential changes in aspen mortality under drier future conditions. For each plot (gray points), panels show mean predicted mortality index changes for plot $i(\Delta M)$ resulting from a decrease of 0.43 in the ln-transformed winter precipitation (1 standard deviation) relative to (a) ln-transformed aspen density, (b) relative basal area, (c) quadratic mean diameter, and (d) forest productivity (increment in basal area), and $\Delta M$ resulting from an increase of 0.21 in the growing-season vapor pressure deficit (1 standard deviation) relative to (e) stand age. Bootstrapped estimates of $95 \%$ confidence intervals (black lines) of mortality index sensitivity for each of 10 forest stand structure, productivity, or age bins (i.e., less than 10th percentile of data, 10th to 20th percentile of the data, and so forth) are also presented. The dashed line indicates no predicted change with decreasing precipitation (a-d) or VPD (e).

most vulnerable to climate-induced mortality (i.e., predicted increase in mortality index with decreasing winter precipitation) for stands with high aspen density, moderate-to-high relative basal area, and with low stand age (Fig. 2a, b, e). Combined with the high correlation between aspen density and relative basal area and the relatively large negative effect of relative basal area on mortality index (Fig. 1; see Appendix B: Table B1), this suggests that interspecific competition may play an increasingly important role in predisposing aspen to drought-induced mortality as aspen-dominated stands begin to be replaced by conifers.

Conversely, low aspen density, low relative basal area, and high-age stands were predicted to experience decreases in mortality index with drought (Fig. $2 \mathrm{a}, \mathrm{b}, \mathrm{e})$, possibly reflecting the post-successional phase when only a remnant of the original aspen stand remains. Presumably, these trees survived encroachment due to some competitive advantage, which might buffer them against climatic stress. Thus, initial mortality due to conifer encroachment may have removed susceptible individuals, leaving only the most robust aspen, which are more likely to continue to survive. Given that aspen is generally a fire-dependent, seral species (i.e., replaced by other species during forest succession in the absence of disturbance) across much of the Rocky Mountain West (Shinneman et al. 2013), these results imply that drought may accelerate aspen mortality in response to 
initial conifer encroachment, potentially speeding up succession.

Surprisingly, mortality index sensitivities to climate indicated that decreasing winter precipitation might lead to weakly increasing mortality indices as forest productivity increases (Fig. 2d). Stand basal area increment may be positively influenced by replacement of aspen by more shade-tolerant conifers through competitive exclusion, which may be able to maintain higher growth rates even at high densities. Alternatively, greater forest productivity could result in shifting aspen allometry, such as decreased tree taper (i.e., increased height-to-diameter ratio), possibly increasing physiological vulnerability to drought (Callaway et al. 1994, Delucia et al. 2000, Frey et al. 2004). However, a study in southwestern Colorado found the opposite effect, but this result may have been confounded by the high correlation between height-todiameter ratio and site index in that study (Worrall et al. 2010). The lack of a negative relationship of basal area increment with $\ln$-transformed aspen density and relative basal area (Pearson correlation $r=0.44$ and $r=0.01$, respectively; Appendix A: Fig. A2) does not support the competitive explanation, but the slight positive relationship between basal area increment and quadratic mean diameter (Pearson correlation $r=0.18$; Fig. A2) supports the physiological explanation. Because the relationship between mortality index sensitivity to decreasing winter precipitation and basal area increment was relatively weak, this pattern may have a minor impact on aspen responses across the region. Our results highlight the need to better understand interactions between competitive environment and tree physiology in determining tree vulnerability to climate.

By examining patterns in dead tree distributions across the region in relation to average climatic conditions, our results shed light on the factors predisposing aspen to death (Frey et al. 2004). As snags stand for several years to decades, they integrate mortality over several years. More importantly, mortality events are not caused by climate (i.e., long-term patterns), but by weather (e.g., extreme events). Thus, our study cannot directly address the proximate factors inciting mortality events, such as extreme drought (Anderegg et al. 2012a) or natural enemy attack (McDowell et al. 2008). In particular, more work is needed to understand the actual mechanisms of tree mortality. Because dead tree abundances provide an integrated measure of mortality over several years, we observed the mortality process indirectly. If increasing decomposition rates in warm and wet environments (Zell et al. 2009) result in dead trees standing longer, mortality index could vary with climate even if mortality did not, resulting in elevated effects of climate. Given the low correlation between non-climatic and climatic variables (Appendix A: Fig. A2) and the relatively weak effects of climate on mortality index (Fig. 1; see Appendix B: Table B1), it is unlikely the climatically varying decomposition rates would cause the interac- tions observed or lead to underestimation of the importance of climate. Therefore, our main conclusions (1) that forest stand structure, productivity, and age play a greater role in explaining patterns of aspen mortality than does climate, and (2) that forest stand structure and productivity mediate the effects of drought, are probably not impacted by variation in decomposition rates.

By accounting for both forest dynamics and climate in explaining patterns of standing dead aspen, our results imply that future warming and drying of aspen forests will result in accelerated succession and aspen conversion to conifer forest. Given that stand development changes could have dramatic consequences if patterns of biomass accumulation are altered or replacement of aspen by conifer species is accelerated, patterns of carbon sequestration and community composition in many forests might be expected to shift. Physiological vulnerability of aspen to drought is predicted to result in large reductions in carbon stocks due to reduced growth (Anderegg 2012) and increased mortality (Huang and Anderegg 2011). Sudden aspen decline impacts the rest of the plant community, including the diverse assemblage of plant species comprising forest understories (Anderegg et al. $2012 b$ ). Altered patterns of forest succession in mixed aspen-conifer stands will probably complicate restoration and forest management activities intended to alter stand development (Smith and Smith 2005). Therefore, ignoring forest succession when examining climate impacts on forest ecosystems may lead to dramatic biases in predictions of regional forest change with future climate.

\section{Acknowledgments}

Funding for this work was provided by the University of Wyoming and the U.S. Geological Survey, Southwest Biological Science Center via cooperative agreement \#G11AC20366 and the NSF Postdoctoral Research Fellowship in Biology \#1202800. The manuscript was improved by comments from three anonymous reviewers. Any use of trade, product, or firm names is for descriptive purposes only and does not imply endorsement by the U.S. Government. Any opinions, findings, and conclusions or recommendations expressed in this material are those of the authors and do not necessarily reflect the views of NSF.

\section{Literature Cited}

Anderegg, W. R. L. 2012. Complex aspen forest carbon and root dynamics during drought. Climatic Change 111:983991.

Anderegg, W. R. L., L. D. L. Anderegg, C. Sherman, and D. S. Karp. 2012b. Effects of widespread drought-induced aspen mortality on understory plants. Conservation Biology 26: 1082-1090.

Anderegg, W. R. L., J. A. Berry, D. D. Smith, J. S. Sperry, L. D. L. Anderegg, and C. B. Field. 2012a. The roles of hydraulic and carbon stress in a widespread climate-induced forest die-off. Proceedings of the National Academy of Sciences USA 109:233-237.

Anderegg, W. R. L., L. Plavcová, L. D. L. Anderegg, U. G. Hacke, J. A. Berry, and C. B. Field. 2013. Drought's legacy: multiyear hydraulic deterioration underlies widespread aspen forest die-off and portends increased future risk. Global Change Biology 19:1188-1196.

Angers, V. A., P. Drapeau, and Y. Bergeron. 2010. Snag degradation pathways of four North American boreal tree species. Forest Ecology and Management 259:246-256.

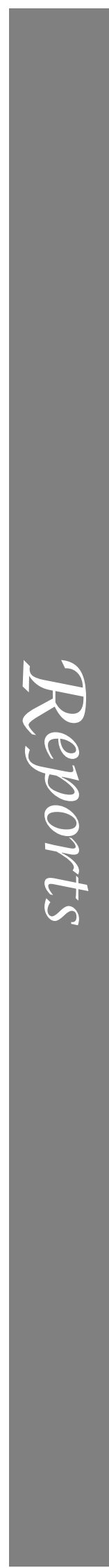


Binkley, D. 2008. Age distribution of aspen in Rocky Mountain National Park, USA. Forest Ecology and Management 255: 797-802.

Callaway, R. M., E. H. DeLucia, and W. H. Schlesinger. 1994. Biomass allocation of montane and desert ponderosa pine: An analog for response to climate change. Ecology 75:14741481.

Delucia, E. H., H. Maherali, and E. V. Carey. 2000. Climatedriven changes in biomass allocation in pines. Global Change Biology 6:587-593.

Frey, B. R., V. J. Lieffers, E. T. Hogg, and S. M. Landhäusser. 2004. Predicting landscape patterns of aspen dieback: mechanisms and knowledge gaps. Canadian Journal of Forest Research 34:1379-1390.

Ganey, J. L., and S. C. Vojta. 2005. Changes in snag populations in northern Arizona mixed-conifer and ponderosa pine forests, 1997-2002. Forest Science 51:396-405.

Gower, S. T., J. G. Vogel, J. M. Norman, C. J. Kucharik, S. J. Steele, and T. K. Stow. 1997. Carbon distribution and aboveground net primary production in aspen, jack pine, and black spruce stands in Saskatchewan and Manitoba, Canada. Journal of Geophysical Research 102:29029-29041.

Hart, J. H., and D. L. Hart. 2001. Heartrot fungi's role in creating picid nesting sites in living aspen. Pages 207-214 in W. D. Shepperd, D. Binkley, D. L. Bartos, T. Stohlgren, and L. G. Eskew, compilers. Sustaining aspen in western landscapes: Symposium Proceedings RMRS-P-18. USDA Forest Service, Rocky Mountain Research Station, Fort Collins, Colorado, USA.

Hicke, J. A., J. C. Jenkins, D. S. Ojima, and M. Ducey. 2007. Spatial patterns of forest characteristics in the western United States derived from inventories. Ecological Applications 17: $2387-2402$.

Hogg, E. H., and J. P. Brandt. 2005. Factors affecting interannual variation in growth of western Canadian aspen forests during 1951-2000. Canadian Journal of Forest Research 35:610-622.

Hogg, E. H., J. P. Brandt, and M. Michaelian. 2008. Impacts of a regional drought on the productivity, dieback, and biomass of western Canadian aspen forests. Canadian Journal of Forest Research 38:1373-1384.

Huang, C.-Y., and W. R. L. Anderegg. 2011. Large droughtinduced aboveground live biomass losses in southern Rocky Mountain aspen forests. Global Change Biology 18:1016-1027.

Kashian, D. M., W. H. Romme, and C. M. Regan. 2007. Reconciling divergent interpretations of quaking aspen decline on the northern Colorado Front Range. Ecological Applications 17:1296-1311.

Kuhn, T. J., H. D. Safford, B. E. Jones, and K. W. Tate. 2011. Aspen (Populus tremuloides) stands and their contribution to plant diversity in a semiarid coniferous landscape. Plant Ecology 212:1451-1463.

Kulakowski, D., M. W. Kaye, and D. M. Kashian. 2013. Longterm aspen cover change in the western US. Forest Ecology and Management 299:52-59.
Lee, P. 1998. Dynamics of snags in aspen-dominated midboreal forests. Forest Ecology and Management 105:263-272.

McDowell, N., et al. 2008. Mechanisms of plant survival and mortality during drought: why do some plants survive while others succumb to drought? New Phytologist 178:719-739.

Mitton, J. B., and M. C. Grant. 1996. Genetic variation and the natural history of quaking aspen. BioScience 46:25-31.

Mock, K. E., et al. 2012. Widespread triploidy in western North American aspen (Populus tremuloides). PloS One 7:e48406.

Peet, R. K., and N. L. Christensen. 1987. Competition and tree death. BioScience 37:586-595.

PRISM Climate Group. 2008, August 22. PRISM climate data. Oregon State University Corvallis, Oregon, USA. http:// www.prism.oregonstate.edu

R Development Core Team. 2010. R: A language and environment for statistical computing. R Foundation for Statistical Computing, Vienna, Austria.

Shinneman, D. J., W. L. Baker, P. C. Rogers, and D. Kulakowski. 2013. Fire regimes of quaking aspen in the Mountain West. Forest Ecology and Management 299:22-34.

Simonson, S. E., P. A. Opler, T. J. Stohlgren, and G. W. Chong. 2001. Rapid assessment of butterfly diversity in a montane landscape. Biodiversity and Conservation 10:1369-1386.

Smith, A. E., and F. W. Smith. 2005. Twenty-year change in aspen dominance in pure aspen and mixed aspen/conifer stands on the Uncompahgre Plateau, Colorado, USA. Forest Ecology and Management 213:338-348.

Williams, A. P., et al. 2012. Temperature as a potent driver of regional forest drought stress and tree mortality. Nature Climate Change 3:292-297.

Worrall, J. J., L. Egeland, T. Eager, R. A. Mask, E. W. Johnson, P. A. Kemp, and W. D. Sheppard. 2008. Rapid mortality of Populus tremuloides in southwestern Colorado, USA. Forest Ecology and Management 255:686-696.

Worrall, J. J., S. B. Marchetti, L. Egeland, R. A. Mask, T. Eager, and B. Howell. 2010. Effects and etiology of sudden aspen decline in southwestern Colorado, USA. Forest Ecology and Management 260:638-648.

Worrall, J. J., G. E. Rehfeldt, A. Hamann, E. H. Hogg, S. B. Marchetti, M. Michaelian, and L. K. Gray. 2013. Recent declines of Populus tremuloides in North America linked to climate. Forest Ecology and Management 299:35-51.

Woudenberg, S. W., B. L. Conkling, and B. M. O'Connell. 2010. The Forest Inventory and Analysis database: Database description and users' manual version 4.0 for Phase 2 . General Technical Report RMRS-GTR-245. USDA Forest Service, Rocky Mountain Research Station, Fort Collins, Colorado, USA.

Zegler, T. J., M. M. Moore, M. J. Fairweather, K. B. Ireland, and P. Z. Fulé. 2012. Populus tremuloides mortality near the southwestern edge of its range. Forest Ecology and Management 282:196-207.

Zell, J., G. Kändler, and M. Hanewinkel. 2009. Predicting constant decay rates of coarse woody debris - A metaanalysis approach with a mixed model. Ecological Modelling 220:904-912.

\section{Supplemental Material}

\section{Appendix A}

Additional figures describing data (Ecological Archives E095-180-A1).

\section{Appendix B}

Model fitting and selection (Ecological Archives E095-180-A2).

\section{Supplement}

Model-fitting code in R (Ecological Archives E095-180-S1). 